\title{
Short Communication: a Simple Nanoparticle - based TiO2 Memristor Device and the Role of Defect Chemistry In Its Operation
}

\author{
Rafaela De Carvalho \\ Technological University Dublin, rafa_cdc@hotmail.com \\ Tony Betts \\ Technological University Dublin, anthony.betts@tudublin.ie \\ John Cassidy \\ Technological University Dublin, john.cassidy@tudublin.ie
}

Follow this and additional works at: https://arrow.tudublin.ie/scschcpsart

Part of the Chemistry Commons

\section{Recommended Citation \\ This Article is brought to you for free and open access by the School of Chemical and Pharmaceutical Sciences at ARROW@TU Dublin. It has been accepted for inclusion in Articles by an authorized administrator of ARROW@TU Dublin. For more information, please contact arrow.admin@tudublin.ie, aisling.coyne@tudublin.ie, gerard.connolly@tudublin.ie.}

de Carvalho, R.C., Betts, A.J. \& Cassidy, J.F. (2019). Short communication: a simple naonparticle-based TiO2 membristor device and the role of defect chemistry in its operation. Journal of Solid State Electrochemistry, pp.1-5 https://doi.org/10.1007/s10008-019-04239-z

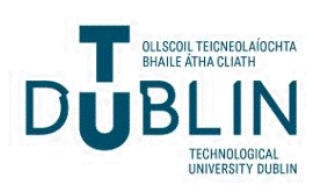




\title{
Short communication: A simple Nanoparticle-Based $\mathrm{TiO}_{2}$ Memristor Device and the Role of Defect Chemistry in its Operation.
}

\author{
Rafaela C de Carvalho ${ }^{\mathrm{a}}$, Anthony J. Betts ${ }^{\mathrm{a}}$. John F. Cassidy a, b \\ a- Applied Electrochemistry Group, FOCAS Research Institute \\ Technological University Dublin, City Campus, Kevin Street, Dublin DO8 NF82, \\ Ireland \\ b- School of Chemical and Pharmaceutical Sciences \\ Technological University Dublin, City Campus, Kevin Street, Dublin D08 NF82 \\ Ireland
}

\begin{abstract}
A simple metal-semiconductor-metal device comprising $\mathrm{TiO}_{2}$ cast from a suspension of Degussa P25 and placed between two metal plates (Al/Al lap shears) demonstrated memristivelike resistive switching behaviour. A mechanism is proposed which relies upon the formation of $\mathrm{p}$ and n-type regions within the P25 semiconductor material ultimately leading to the formation of a p-n junction. This device also exhibited enhanced steady state currents upon the imposition of potential steps, most notably at higher potential magnitudes (both anodic and cathodic). Indicating lack of ionic conduction.
\end{abstract}

\section{Keywords}

$\mathrm{TiO}_{2}$, Degussa P25, memristor, nanoparticles, point defects.

\section{Introduction}

There has been considerable interest in the fabrication and understanding of the operation of Resistive Random Access memory (RRAM or ReRAM) or memristor devices in recent years [1-3]. Typical structures comprise a metal-semiconductor-metal (MSM) configuration with $\mathrm{TiO}_{2}$ being a popular semiconductor material. Indicators of bipolar resistance switching include a "figure of eight" current-potential profile, along with a transition from a high resistance state to a low resistance state [4].

There have been a number of mechanisms proposed for the operation of a memristor. These include Mott transition, Schotty Barrier behaviour at the interface, charge trapping or detrapping, polaron melting and ordering, electric field-induced generation of crystalline 
defects and creation or destruction of a conducting filament [5]. An electrochemical model based on ionic movement within the interlayer has also been proposed [6-7]. However, the model which is most often proposed in reviews of memristor operation is the conductive filament or thermoelectric model $[1,2,8,9,10$ and 11]. The oxygen vacancies formed at the anode migrate to the other electrode and are responsible for the transition from a high resistance state (HRS) to a low resistance state (LRS) [1]. Models involving conducting filament growth refer to oxygen ion current and propose a very high local temperature rise for filaments; up to $1000^{\circ} \mathrm{C}[11]$. The main issue with this model is that charge transport through the insulating layer is highly hindered.

At room temperature electrical conductivity $(\sigma)$ in transition metal oxides such as $\mathrm{TiO}_{2}$ is the sum of the product of both electron (n) and hole concentrations (p) and mobility terms ( $\mu_{\mathrm{n}}$ and $\mu_{\mathrm{p}}$ respectively) and is given by $\mathrm{e}\left(\mathrm{n} \mu_{\mathrm{n}}+\mathrm{p} \mu_{\mathrm{p}}\right)$ where e is the elementary charge [25]. Under ambient conditions the ionic conductivity component, $\sigma_{i}$ which normally contributes is negligible. It assumes substantial values only at highly elevated temperatures.

Although various models have been proposed to explain resistive switching behaviour in the $\mathrm{TiO}_{2}$ layer, the nature of charge transport in such devices is still the subject of much debate. For example Lim and Ismail in their review of conduction mechanisms of resistive switching devices reported a range of different mechanism sometimes for the same device [29]. In this work a new model is proposed based on concepts derived from point defect models in conjunction with the operation of an electrolytic cell utilising electron and electron hole carriers within the semiconducting $\mathrm{TiO}_{2}$ solid state electrolyte sandwiched between two aluminium plates. 


\section{Experimental}

A suspension of $\mathrm{TiO}_{2}$ (Degussa P25, $0.076 \mathrm{~g}$ ) was prepared in 2-propanol $\left(10 \mathrm{~cm}^{3}\right) .10 \mu \mathrm{L}$ of this suspension was then placed on an aluminium plate or lap shear (dimensions of $10 \mathrm{~cm} \times$ $2.5 \mathrm{~cm} \times 2 \mathrm{~mm})$. The general scheme of the device structure is shown in Fig.1. A potentiostat (CHI 600A) was used to apply a potential, where the reference and auxiliary connections were linked to one lap shear, while the working electrode connection was linked to the other. Using this equipment, potentials lower than $0.6 \mathrm{~V}$ were typically applied, in order to prevent current overload of the potentiostat. An AFM measurement of the $\mathrm{P} 25 \mathrm{TiO}_{2}$ layer indicated it was 40 $\mathrm{nm}$ in thickness.

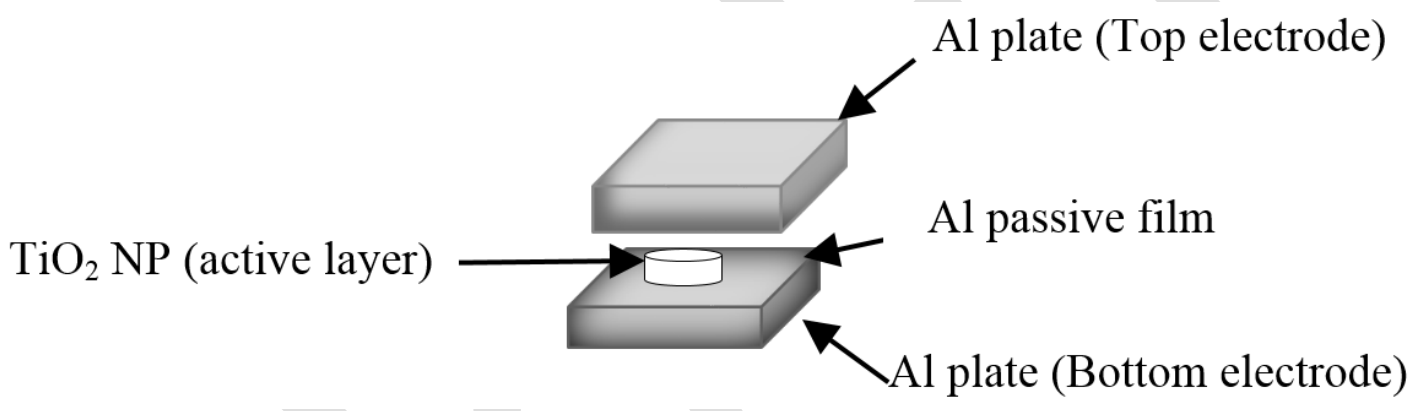

Figure 1 Device arrangement. $\mathrm{TiO}_{2} \mathrm{NP}$ were cast from a suspension which was allowed to dry on an $\mathrm{Al}$ plate. A second Al plate was then clamped on top to form a sandwich-like assembly

\section{Results and discussion}

It is important to highlight that in the literature, there have been many memristors for which a control was not mentioned. Figure 2 is a cyclic voltammogram (plot of current as a result of a linear potential ramp) of such a control assembly consisting of an aluminium lap shear clamped directly on top of another aluminium lap shear. As expected, the result is an Ohm's law plot where the resistance is calculated to be $5 \Omega$. 


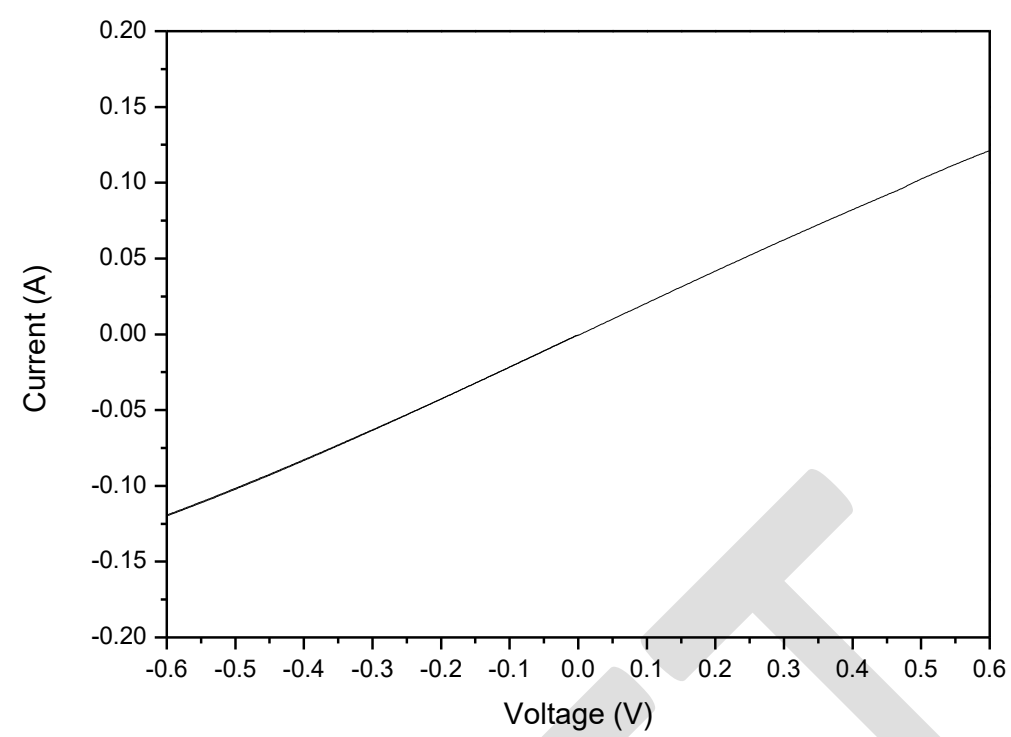

Figure 2 Plot showing the typical ohmic behaviour of a blank (control) device comprising two plates Al/Al lap shears clamped together. Scan rate $=10 \mathrm{mV} / \mathrm{s}$

Figure 3 shows typical current-voltage $(I-V)$ data of an $\mathrm{Al} / \mathrm{TiO}_{2} / \mathrm{Al}$ assembly. This data was obtained from imposition of a potential scan rate of $0.1 \mathrm{~V} / \mathrm{s}$ over an applied potential range of -0.5 to $+0.5 \mathrm{~V}$. The initial starting potential was $0 \mathrm{~V}$. The current in this figure appears to be much larger than those most often reported in the literature, since most assemblies in the literature are prepared using micro fabrication facilities, yielding significantly smaller surface contact areas [12]. However for this simple device the contact area of the $\mathrm{P} 25 \mathrm{TiO}_{2}$ layer sandwiched between the two aluminium plates is much greater; of the order of $0.5 \mathrm{~cm}^{2}$. 


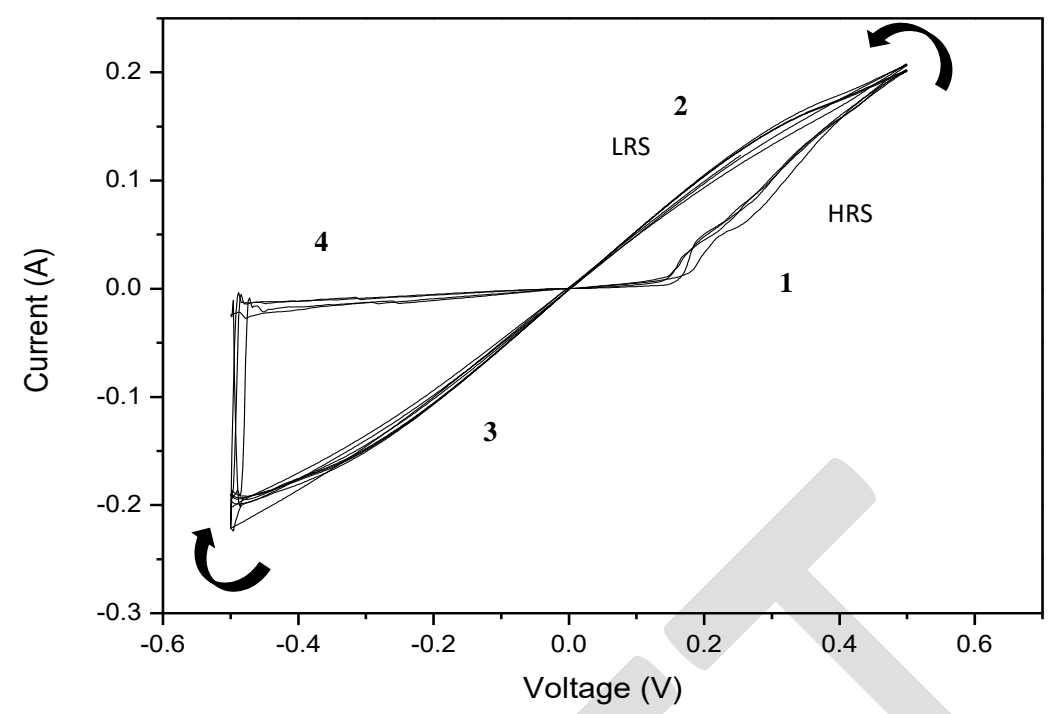

Figure 3 A plot of current against the potential displaying typical behaviour of a bipolar memristor of a structure of $\mathrm{Al} / \mathrm{TiO}_{2} / \mathrm{Al}$ assembly. $\mathrm{Al}$ lap shear is connected to the working electrode connection and the other is connected to the counter + reference electrode connections

Figure 3 shows a triangular curve that exhibits a clear hysteresis and asymmetric switching behaviour. For the sake of clarity only 6 cycles are shown in Fig. 3 , where the first three initial scans are overlaid together with the $28^{\text {th }}, 29^{\text {th }}$ and the $30^{\text {th }}$ consecutive scans. Similar behaviour was demonstrated by Gale et al for $\mathrm{Al} /$ sol-gel $\mathrm{TiO}_{2} / \mathrm{Al}$ and by other authors $[13,14]$.The clear advantage of this device is its ease of construction.

It should be stressed that for the $\mathrm{Al} / \mathrm{TiO}_{2} / \mathrm{Al}$ device, there is a possible effect of the aluminium oxide layer, or even a more complex mixed phase (hydrated aluminium oxide) which may well act as a source of holes $\left(\mathrm{h}^{\bullet}\right)$. The chemical reaction between an Al top/bottom electrode and an amorphous sol-gel $\mathrm{TiO}_{2}$ has been confirmed experimentally by Jeong et al using high-resolution transmission electron microscopy (HRTEM), an analytical TEM technique using energy-filtering transmission electron microscopy (EFTEM), and an in situ xray photoelectron spectroscopy (XPS) [14]. 
Such findings have been proposed and supported by different research groups, which suggests that there is an oxygen deficiency present in the middle region of $\mathrm{TiO}_{2}$ [14-15]. It contradicts the belief that oxygen vacancies at the metal-oxide interface play a critical role on the reversible switching between a high resistance state and a low resistance state. It should be noted that $\mathrm{Al} / \mathrm{TiO}_{2} / \mathrm{Al}$ is more correctly represented as $\mathrm{Al} / \mathrm{Al}_{2} \mathrm{O}_{3}(\mathrm{OH}) / \mathrm{TiO}_{2} / \mathrm{Al}_{2} \mathrm{O}_{3}(\mathrm{OH}) / \mathrm{Al}$, however, the conventional representation is $\mathrm{Al} / \mathrm{TiO}_{2} / \mathrm{Al}[28]$.

In pure $\mathrm{TiO}_{2}$ samples (such as Degussa P25) at high temperatures (typically above 1273 $\mathrm{K}$ ), the following equilibria describing defect chemistry reactions can happen [16]. This can result in either the creation of n-type $\mathrm{TiO}_{2}$ (equations (1)-(3)) or p-type $\mathrm{TiO}_{2}$ (equation (4)), represented by Kröger-Vink notation, where $(\bullet \bullet)$ represents a double positive charge and (e') signifies a negatively charged electron.

$\mathrm{O}_{\mathrm{o}}^{x} \leftrightarrows \mathrm{V}_{\mathrm{o}}^{\bullet \bullet}+2 \mathrm{e}^{\prime}+1 / 2 \mathrm{O}_{2}$

$2 \mathrm{O}^{x}{ }_{\mathrm{o}}+\mathrm{Ti}^{x} \mathrm{Ti}_{\mathrm{i}} \leftrightarrows \mathrm{Ti}_{\mathrm{i}}^{\bullet \bullet \bullet}+3 \mathrm{e}^{\prime}+\mathrm{O}_{2}$

$2 \mathrm{O}^{x}+\mathrm{Ti}^{x} \mathrm{Ti} \leftrightarrows \mathrm{Ti}_{\mathrm{i}}^{\bullet \bullet \bullet \bullet}+4 \mathrm{e}^{\prime}+\mathrm{O}_{2}$

$\mathrm{O}_{2} \leftrightarrows 2 \mathrm{O}_{\mathrm{o}}^{x}+\mathrm{V}_{\mathrm{Ti}}{ }^{\prime \prime \prime}+4 \mathrm{~h}^{\bullet}$

Also $\mathrm{V}_{\mathrm{o}} \bullet \bullet$ corresponds to an oxygen vacancy, with a double positive charge. Equation (1) explains why the presence of oxygen vacancies has been attributed to an n-type $\mathrm{TiO}_{2}$ semiconductor. In this notation, $\mathrm{Ti}_{\mathrm{i}}{ }^{\bullet \bullet \bullet}$ denotes $\mathrm{Ti}^{3+}$ in an interstitial site and $\mathrm{Ti}_{\mathrm{i}}{ }^{\bullet \bullet \bullet}$ represents $\mathrm{Ti}^{4+}$ in an interstitial site. In these reactions $\mathrm{e}^{\prime}$ is a $\mathrm{Ti}^{3+}$ atom in a titanium lattice site (quasi-free electron) and $\mathrm{h}^{\bullet}$ is an $\mathrm{O}^{-}$anion in an $\mathrm{O}^{2-}$ lattice site (a quasi-free hole) [17].

Figure 4 displays the currents obtained from the application of selected constant potentials (in $0.1 \mathrm{~V}$ increments) for a period of $10 \mathrm{~s}$. The resulting constant current indicates a resistive behaviour. This confirms that the current is produced by the rapid movement of 
electrons or holes rather than from ionic species. However, the current behaviour is different when a positive potential is applied compared to when a negative potential is applied. In the case of the high negative potentials $(-0.4 \mathrm{~V}$ and $-0.5 \mathrm{~V})$, an initial current decay is evident before a steady state current was attained.

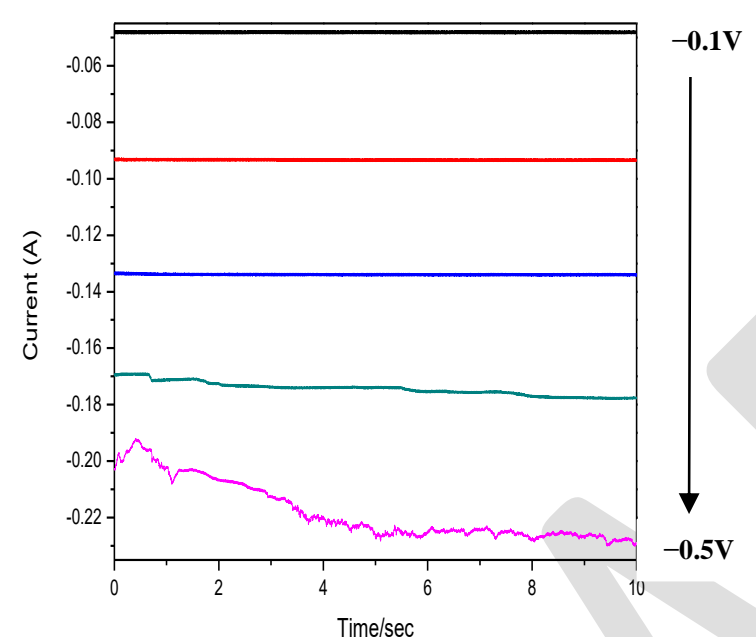

(a)

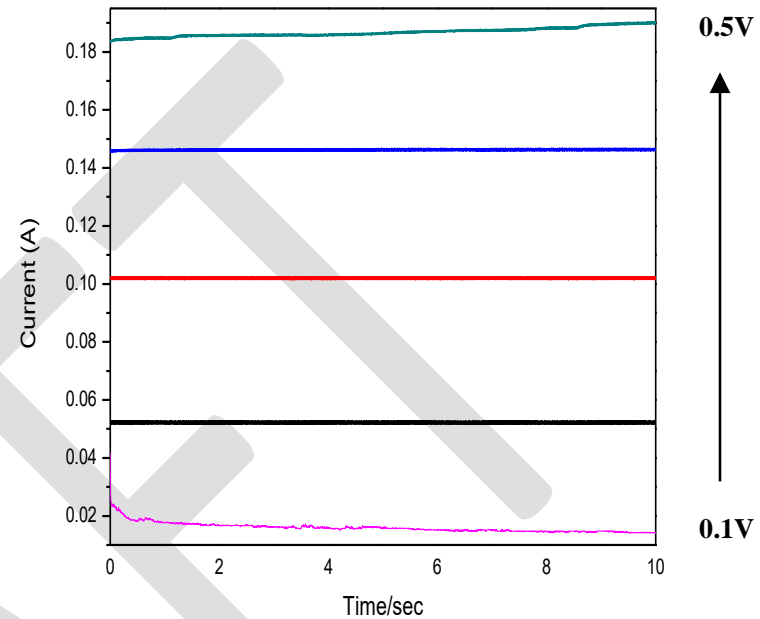

(b)

Figure 4 Current transient at fixed potentials for $10 \mathrm{~s}$ in $0.1 \mathrm{~V}$ steps ranging from $0.1 \mathrm{~V}$ to $0.5 \mathrm{~V}$ on right (a) and $-0.1 \mathrm{~V}$ to $-0.5 \mathrm{~V}$ on left side for $\mathrm{Al} / \mathrm{TiO}_{2} / \mathrm{Al}(\mathrm{b})$

This initial decay is possibly influenced by the dual layer $\mathrm{Al}_{2} \mathrm{O}_{3} /(\mathrm{OH})$ passive film created and the chemical change of the titanium oxide thin layer sandwiched between two aluminium electrodes [18-19]. In the $\mathrm{Al} / \mathrm{TiO}_{2} / \mathrm{Al}$ device the space charge layer is forward biased, which leads to the generation of a low resistance state and ultimately a constant current at both positive and negative fixed potentials. Such constant currents are not observed for the mass transport of ionic species, only at p-n junctions, where the movements of electrons and holes suggests a non-diffusional behaviour.

Degussa P25 $\left(\mathrm{TiO}_{2}\right)$ comprises a mixture of anatase and rutile nanoparticles (in the ratio 80:20) with an average size of $21 \mathrm{~nm}$. SEM images of this material indicates that it forms 
nodules with a porosity level of about 30-40\% [20-21].Initially a white powder once disaggregated it is translucent. This material is manufactured at high temperatures, typically ranging between $1273 \mathrm{~K}$ and $2673 \mathrm{~K}$ [22]. As a consequence of being formed at such high temperatures, Degussa $\mathrm{P} 25 \mathrm{TiO}_{2}$ is inherently non-stoichiometric in nature and contains various point defects including quasi-free electrons and quasi-free electron holes, oxygen vacancies, titanium vacancies and titanium interstitials as reported in Nowotny et al [25]. In practice such defects arise from the processing conditions (such as production temperature) and the presence of either reducing (hydrogen-rich) or oxidising (oxygen-rich) environments. These defects may react according to the equilibria described by equations 1-4 above.

Sometimes small impurity levels may also act as dopants and can alter the semiconductor's band gap. In fact Degussa P25 ( $\left.\mathrm{TiO}_{2}\right)$ serves as the archetypal photoelectrochemical catalyst and is known to operate through the movement of electrons and holes at room temperature in a wide range of photoelectrochemical processes including generation of solar hydrogen fuel and photocatalysis of organic compounds for waste water purification [25].

When the Degussa P25 $\left(\mathrm{TiO}_{2}\right)$ is connected between two metal electrodes in a memristor configuration such as the assemblies described previously and a positive potential is applied (region 1 in Figure 3), then oxidation occurs at the anode (equation (5)) to form a p- type $\mathrm{TiO}_{2}$. In this case $\mathrm{V}_{\mathrm{o}} \bullet \bullet$ remains, while the electrons pass into the electrode and oxygen is evolved. This electrochemical evolution of oxygen has been observed experimentally in $\mathrm{TiO}_{2}$ based memristor assemblies [5,13,23].

$$
\mathrm{O}^{x} \rightarrow \mathrm{V}_{\mathrm{o}}^{\bullet \bullet}+2 \mathrm{e}^{\prime}+1 / 2 \mathrm{O}_{2}
$$

Alternatively the anode material may also be oxidised $[13,23]$. 


$$
2 \mathrm{Al}+{ }^{3} / 2 \mathrm{O}_{2} \rightarrow 3 \mathrm{~V}_{\mathrm{o}}^{\bullet \bullet}+\mathrm{Al}_{2} \mathrm{O}_{3}+6 \mathrm{e}^{\prime}
$$

Meanwhile, at the cathode n-type $\mathrm{TiO}_{2}$ is formed through the reaction [23]:

$$
2 \mathrm{Ti}^{x} \mathrm{Ti}^{\prime}+2 \mathrm{e}^{\prime} \rightarrow 2 \mathrm{Ti}^{\mathrm{Ti}^{\prime}}
$$

In this case $\mathrm{Ti}_{\mathrm{Ti}}{ }^{\prime}$ corresponds to a $\mathrm{Ti}^{3+}$ species in a $\mathrm{Ti}^{4+}$ vacancy leading to an overall single negative charge $[24,25]$. Such an electrochemical reduction has previously been reported by Gale et al [13] and is widely reported in the literature [13, 23, 24]

Therefore, at the negative electrode (cathode) n-type $\mathrm{TiO}_{2}$ forms and at the anode p-type $\mathrm{TiO}_{2}$ is created at the same time. The operation of p-type $\mathrm{TiO}_{2}$ at room temperature has been reported by Nowotny et al [30].

In the low resistance state, a forward biased p-n type junction appears when the p-type and n-type regions extend from the metal electrode surfaces and meet in the middle with enhanced current carrying capability. This accounts for the resulting increase in current at about -0.16 to $0.5 \mathrm{~V}$ in Figure 3. During the initial electrochemical reaction (5) and (6) $\mathrm{O}^{2-}$ anions migrate to the anode and this has been observed experimentally [5] Thus at the cathode the formation of $\mathrm{Ti}_{n} \mathrm{O}_{2 n-1}$ (eg $\mathrm{Ti}_{2} \mathrm{O}_{3}$ or possibly even a Magnéli phase) occurs [3]. Once the $\mathrm{n}$ and p region are formed the charge is subsequently passed by electron and hole movement as shown in the schematic presented in Figure 5(a) and (b).

(a)

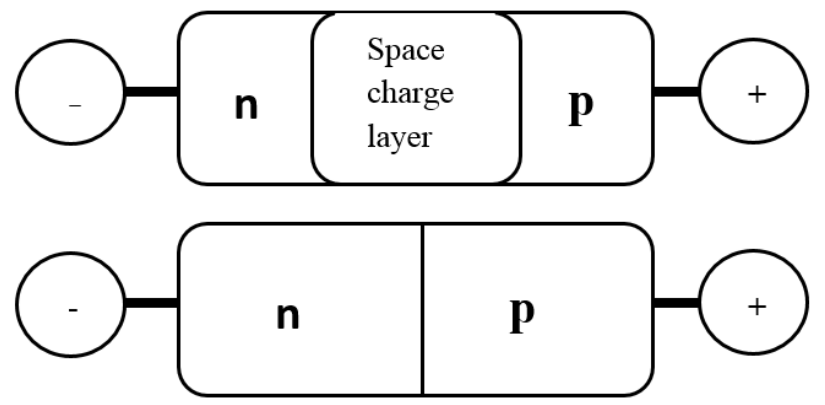

(b) 
Figure 5 (a) Model for the transition from insulator to semiconductor in region 1 of figure 3. (b) A fully semiconducting memristor responsible for the increase in current in region 2 of figure 3

In region 2 (from $0.5 \mathrm{~V}$ to $0.0 \mathrm{~V}$ ), in figure 3 there is a decrease in the applied potential and a corresponding decrease in the driving force of the current.

In contrast, in region 3 (from $0.0 \mathrm{~V}$ to $-0.5 \mathrm{~V}$ ) in figure 3 there is a reversal of the reactions (5) and (6) mentioned above. While regions 1 and 2 operate to increase the population of the electrons and holes at the cathode and anode respectively, in region 3 these populations decrease. However there is a residual build-up of $\mathrm{O}_{2}$ (effectively $\mathrm{h}^{\bullet}$ ) and $\mathrm{Ti}(\mathrm{III})$ species (e') which still allows for a reasonable current through the reversal of the original reactions $(5,6)$ and (7). By the time we get to region 4 (from $-0.5 \mathrm{~V}$ to $0.0 \mathrm{~V}$ ) the movement of electrons and holes has decreased substantially, and the device returns rapidly to its original high resistance state. Fig 5 shows a schematic representation of the process.

The $I-V$ plot presented in Figure 3 is not symmetric; which has been seen in other devices produced micro lithographically $[12,14]$. Indeed a characteristic of our device is its simplicity; it can be produced without vacuum or microlithographic techniques. Thus it is a platform which can be modified using ink jet [26] or screen-printing techniques [27].

\section{Conclusions}

The field of memristors is rapidly growing; a recent reference lists a table of commercial devices along with their characteristics [1]. In this paper a device of very simple construction utilising cystalline Degussa $\mathrm{P} 25 \mathrm{TiO}_{2}$ is demonstrated along with a new semiconductor model of resistive switching operation ascending from point defect chemistry concepts involving the formation of a $\mathrm{p}-\mathrm{n}$ junction arising from formation of $\mathrm{n}$ and $\mathrm{p}$ type regions within a solid state electrolyte is proposed. 


\section{Acknowledgements}

The authors gratefully acknowledge the award of a DIT Fiosraigh Dean of Graduate Studies award to R de Carvalho and COST Action MP1407 (e-MINDS).

References

1 -Ye C, Wu J, He G, Zhang J, Deng T, He P, Wang H (2016) J Mat Sci Tech 32:1-11

2 -Pan F, Gao S, Chen C, Song C, Zeng F (2014) Mater Sci Eng R 83:1-59

3 - Gale E (2014) Semicond Sci Tech 29:104004-104014

4 - Yoo J, Lee K, Tighineanu A, Schmuki P (2013) Electrochem Comms 34:177-180

5 - Gao P, Wang Z, Fu W, Liao Z, Liu K, Wang K, Bai X, Wang E (2010) Micron 41:301305

6 - Cassidy JF, Fox, D, Betts AJ (2016) J Solid State Electrochem 20:1229-1234

7 - Shoute LCT, Pekas N, Wu Y, McCreery RL (2011) Appl Phys A Mater Sci Process 102:841-849

8 -Senthilkumar V, Kathalingam A, Kannan V, Rhee, JK (2012) Microelectronic Eng 98: 97100

9 - Szot K, Speier W, Bihlmayer G,Waser R (2006) Nat Mater 5:312-320

10 - Salaoru I, Prodromakis T, Khiat A,Toumazou C (2013) Appl Phys Lett 102:13506-13509

11 -Kalaev D, Yalon E, Reiss I (2015) Solid State Ionics 276: 9-17

12 - Gale E, Mayne R, Adamatzky A, Costello BL (2014) Mater Chem Phys 143: 524-529

13 - Gale E, Pearson D, Kitson S, Adamatzky A, Costello BL (2015) Mater Chem Phys 162: 20-30

14 - Jeong HY, Lee, JY, Choi SY, Kim JW (2009) Appl Phys Lett 95:162108-16211

15- Yang JJ, Miao F, Pickett MD, Ohlberg DAA, Stewart DR, Lau CN, Williams RS (2009) Nanotech 20:215201-215205 
16 - Nowotny MK, Sheppard LR, Bak T, Nowotny J (2008) J Phys Chem C 112: 5275-5300

17- Bak T, Nowotny J , Sucher N J, Wachsman E (2011) J Phys Chem C 115:15711-15738

18 - Lee S, White HS (2004) J Electrochem Soc 151: B479-B483

19 - McCafferty E (2003) Corrosion Science 45:301-308

20 - Teixeira S, Martins PM, Lanceros-Méndez S, Kühn K, Cuniberti G (2016) Applied Surface Science 384:497-504

21- Ohtani B, Prieto-Mahaney OO, Li D, Abe R (2010) J Photochem Photobio A: Chemistry 216:179-182

22- Boehm HP, Kolloid ZZ (1968) J Chem Soc 227:17-20

23- Waser R, Aono M (2007) Nat Mater 6:833-840

24- Dash CS, Sahoo S, Prabaharan S (2018) Solid State Ionics 324:218-225

25 - Nowotny J, Alim MA, Bak T, Idris MS, Ionescu M, Prince K, Sahdan MZ, Sopian K, Teridi MAM, Sigmund W (2015) Chem Soc Reviews 44:8424-8442

26 - Duraisamy N, Muhammad NM, Kim HC, Jo JD, Choi KH (2012) Thin Solid Films 520: 5070-5076

27- Lien DH, Kao ZH, Huang TH, Liao YC, Lee SC, He JH (2014) ACS Nano 8:7613-7618

28 - Bunker BC, Nelson GC, Zavadil KR, Barbour JC, Wall FD, Sullivan JP, Engelhardt MH, Baer DR (2002) J Phys Chem 106:4705-4713

29 - Lim EW, Ismail R, (2015) Electronics 4:586-613

30 - Nowotny MK, Bogdanoff P, Dittrich T, Fiechter S, Fujishima A, Tributsch H (2010) Mater Lett 64:928-930 